\title{
Failure of pillar of sports and entertainment hall structure
}

\author{
Tomasz Trapko ${ }^{1}$, Michat Musial ${ }^{1, *}$, and Andrzej Ubysz ${ }^{1}$ \\ ${ }^{1}$ Wroclaw University of Science and Technology, Faculty of Civil Engineering, \\ Wybrzeże Wyspiańskiego 27, 50-370 Wrocław, Poland
}

\begin{abstract}
This paper deals with the failure of one of the sports and entertainment halls in Poland. The facility was built in the years 1977-85. Its main load-bearing members were three-hinged double-sloped frames with a total span of $45 \mathrm{~m}$. The main girders of the frames were made of glued-laminated timber. The girders rest on reinforced concrete pillars. Because of the considerable expansion forces the facility was founded on concrete padstones. In the summer of 2016 one of the reinforced concrete pillars was found to have failed. It was established that the failure condition was mainly due to construction errors. A way of strengthening all the pillars with additional RC members was proposed.
\end{abstract}

\section{Introduction and general description of facility}

The sports and entertainment hall was built in Poland in the mid-1980s. Its west and south elevations are shown in fig. 1. The hall houses a full-size $(20 \mathrm{~m} \times 40 \mathrm{~m})$ handball pitch, an amenity area and stands with 800 seats. The construction of the hall began in 1977, but the facility was put in operation as late as in 1985. The facility had been designed by Professor Wojciech Zabłocki. It may be of interest to know that he is not only an outstanding architect, but also a well-known fencer, the winner (as a team) of three Olympic medals (Melbourne'56, Rome'60, Tokyo'64) and the many times world fencing championships medallist (both as an individual and a team).

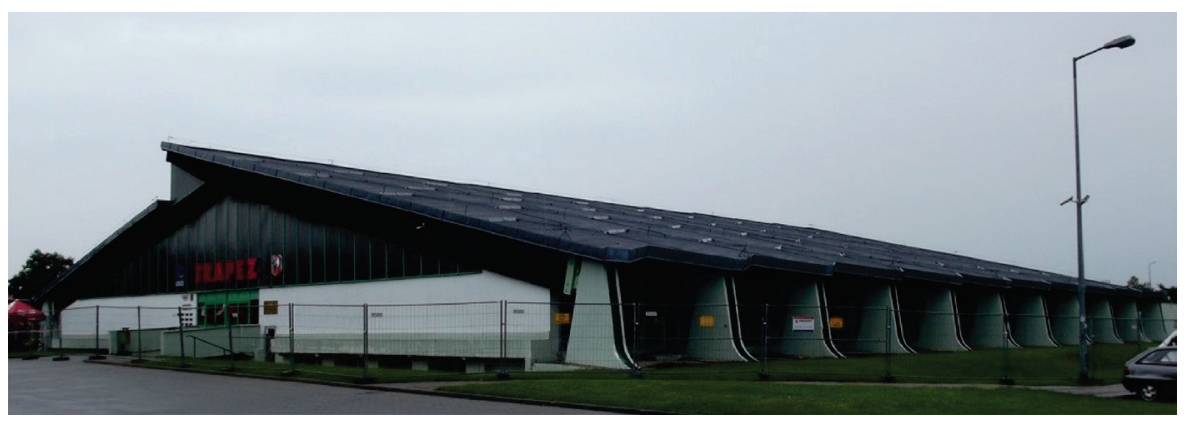

Fig. 1. South and west elevations (with main entrance) [1].

\footnotetext{
*Corresponding author: michal.musial@pwr.edu.pl
} 
The facility's principal load-bearing structure consists of 11 three-hinged frames spaced at every $6.00 \mathrm{~m}$. A typical cross section of the frame is shown in fig. 2 . On plan the structure occupies a $45 \mathrm{~m} \times 60 \mathrm{~m}$ rectangular area. The roof framework is wooden. The main roof girts are made of glued-laminated timber and their dimensions are: $2 \times 14 \mathrm{~cm} \times 124 \mathrm{~cm}$ (no. 1 in fig. 2) and $28 \mathrm{~cm} \times 124 \mathrm{~cm}$ (no. 2). They are joined together with a steel hinge.

$\mathrm{X}$-type bracings, made of beams $12 \mathrm{~cm} \times 30 \mathrm{~cm}$ in cross section, were used in all the fields of the roof planes. Nine pairs of bracings were made in the longer roof plane between the main girders, and five pairs in the shorter roof plane.

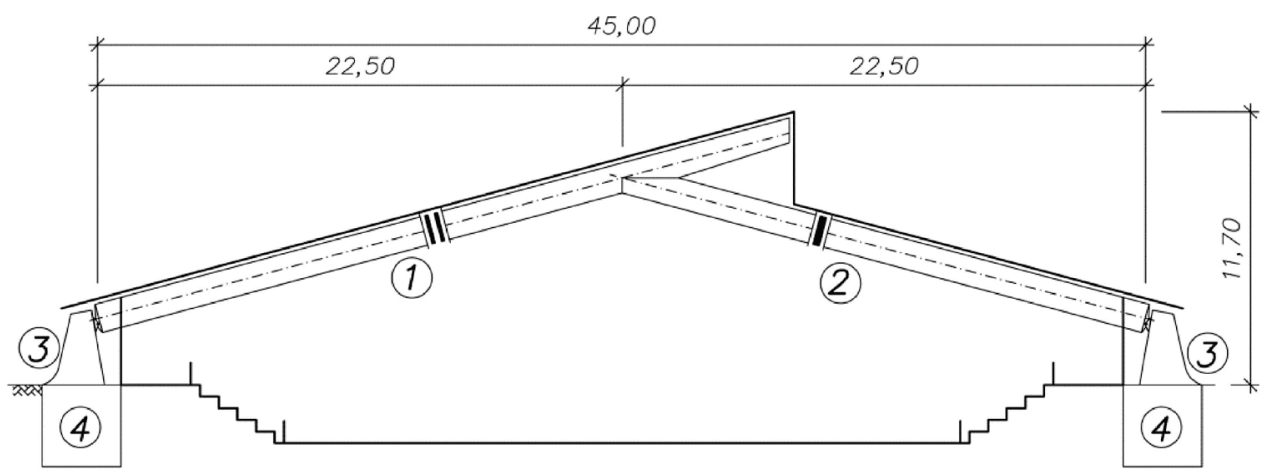

Fig. 2. Typical cross section of hall (dimensions in $m$, description in text) [1].

The wooden girders rest, via steel bearings, on reinforced concrete columns (no. 3) with a tapered cross section with dimensions $\mathrm{b} \times\left(\mathrm{h}_{\min } \div \mathrm{h}_{\max }\right)=60 \mathrm{~cm} \times(70 \div 210) \mathrm{cm}$. The columns were to be anchored (the anchoring proved to be ineffective) in the $180 \mathrm{~cm} \times 300 \mathrm{~cm}$ and $360 \mathrm{~cm}$ deep concrete padstones (no. 4).

\section{Failure condition. Structural defects}

In the summer of 2016, during clean-up work, one of the supporting columns on the facility's south side was found to be damaged. In the zone of the joint with the concrete padstone the cover of concrete debonded extensively along the length of the lap of the starting foundation rebars and the tension reinforcement of the column (fig. 3). At the same time the column turned relative to its compression zone and a gap appeared between the column and the foundation. In its widest part the gap was 3.5 wide. Numerous cracks (most with allowable width) were found on the column's sides. A macroscopic visual examination of the other structural members did not reveal any other negative effects of the failure. This could be owing to the static system (the three-hinged frame), the interaction (via the bracings) between the individual frames in carrying loads and the adaptation properties of the wood.

As the column was damaged, a direct survey of its reinforcement could be carried out. Eight ribbed bars $16 \mathrm{~mm}$ in diameter, made of steel with the characteristic yield strength of $410 \mathrm{MPa}$, extended from the concrete padstone. The bars were joined by a $59-65 \mathrm{~cm}$ long lap splicing with the column's reinforcement of the same density ( 8 steel ribbed bars $16 \mathrm{~mm}$ in diameter), but made of steel with the characteristic yield strength of $355 \mathrm{MPa}$. The reinforcement starting from the foundation and the column's reinforcement suffered from corrosion, with the corrosive losses estimated at $10 \%$. No lateral reinforcement was found in the exposed area. Also above this area examinations carried out by means of a reinforcement detector did not show any lateral rebars. In the gap which had appeared at the 
joint there were no vertical rebars along the column's longer side. The concrete cover of the exposed rebars amounted to $5-15 \mathrm{~mm}$. All the other columns were examined using the reinforcement detector. The same faulty reinforcement layout was found.

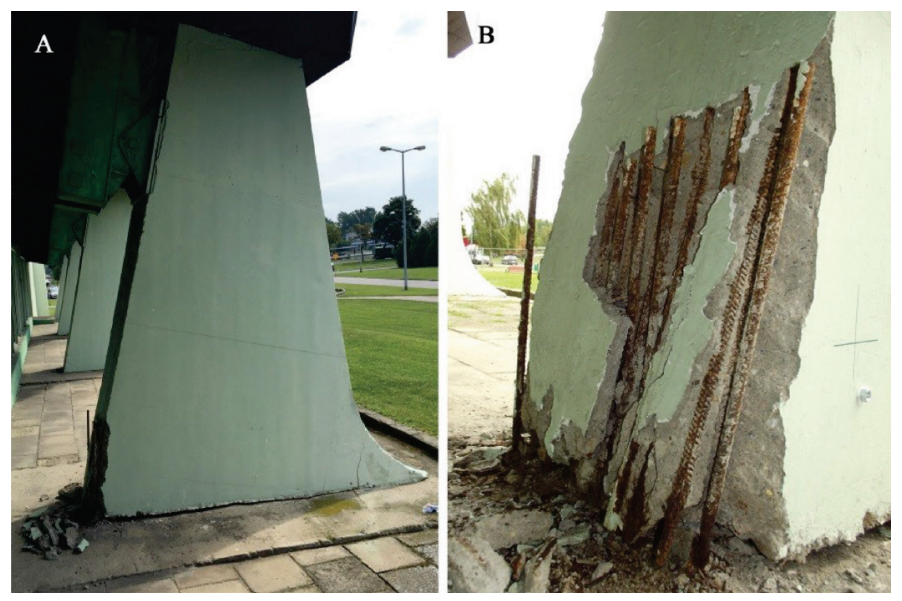

Fig. 3. Damaged column (A - overview, B - place of damage initiation) [1].

Destructive tests, consisting in taking core samples from the columns and the concrete padstones, were carried out [1]. Concrete grades: C30/37 and C20/25, respectively, were found. Comparing the identified concrete strength classes with the current recommendations concerning structural durability [2], the class of the concrete in the pillars can be regarded as satisfactory. Whereas the class of the concrete in the padstones should be higher. However, considering the overall dimensions and the absence of reinforcing rods near the surfaces, the too low class of the foundation concrete did not require an intervention.

\section{Design check calculations}

The reactions originating from the roof framework are of key importance for the stress intensity level in the reinforced concrete pillars. In order to determine most accurately their values a spatial bar structure model (fig. 4) was used and static linear analyses were carried out [3].

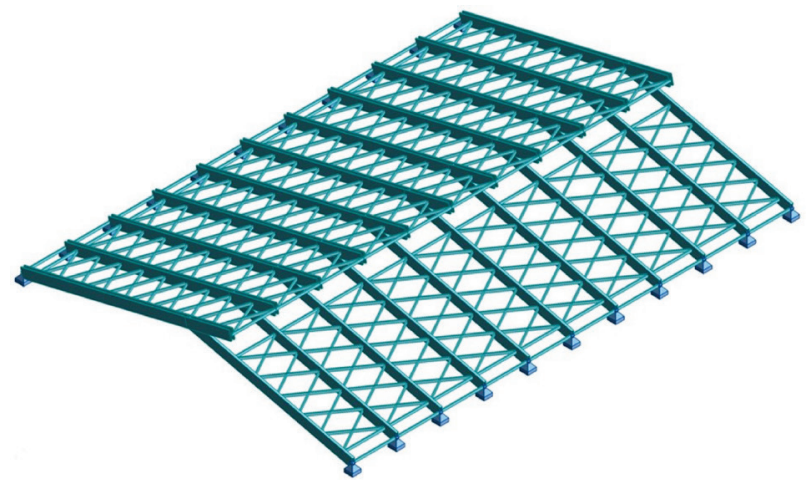

Fig. 4. Numerical model of structure [1]. 
The roof bracings consisted of two types of bars: full (girder-to-girder) bars and cut (girder-to-bracing) bars. This fact was taken into account in the computational model. The interconnections between the girders and the support were modelled as hinged.

Static load calculations were performed in accordance with [4]. The following loads were taken into account: the deadweight of the structure, the deadweight of the roof cover, the snow load and the wind load. Weightless panels were adopted in the computational model to determine the distribution of the roof plane loads among the main load-bearing members.

The resultant maximum design vertical reactions (denoted as 3D-V) and horizontal reactions (denoted as 3D-H) for the individual supports are presented in the chart (fig. 5). Also the reactions computed in the planar system (denoted as 2D) for the load originating from the band corresponding to the spacing of the frames is included. The differences between the values yielded by the $3 \mathrm{D}$ model and the $2 \mathrm{D}$ model can be regarded as negligible for the 3-9 supports.

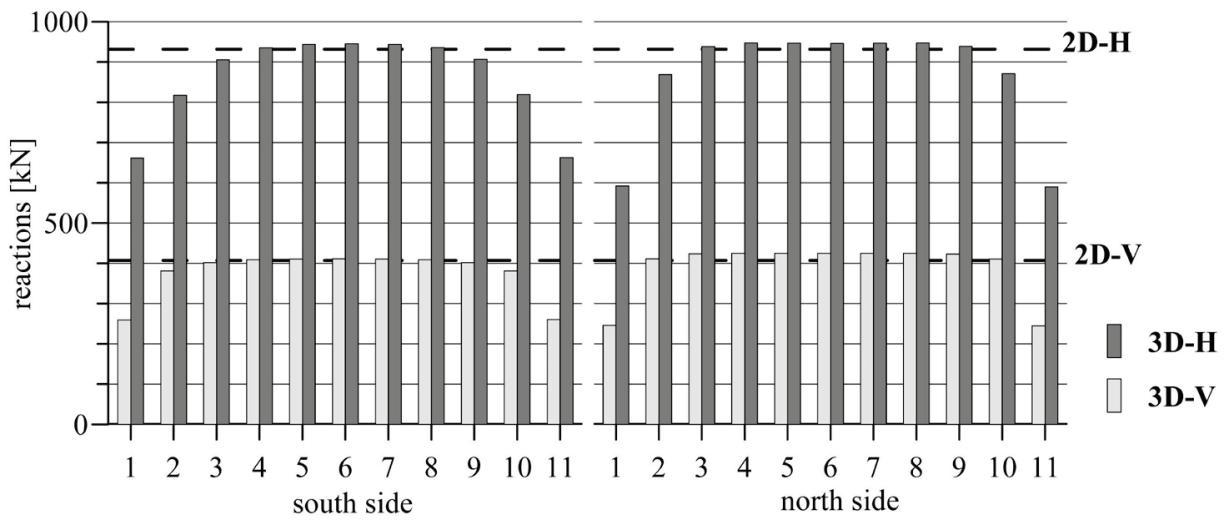

Fig. 5. Maximum design reactions [1].

An interaction curve [5], which can be equated with the load-carrying effects, was plotted for the analysed columns. The bending moment and the axial force, resulting from the interactions, were calculated on the basis of the maximum reactions acting on the damaged column. The results are compared in the diagram shown in fig. 6 .

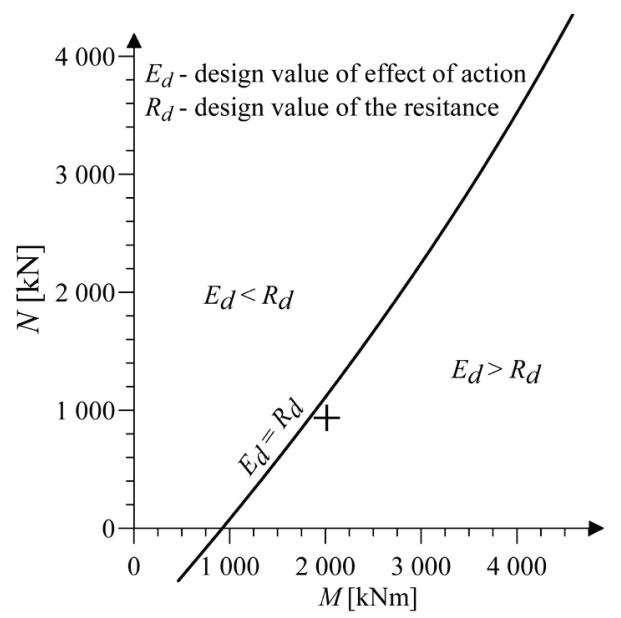

Fig. 6. Interaction force and cross sectional forces for damaged column. 
The design check calculations showed a relatively small exceedance of the load-bearing capacity, which cannot be regarded as the single direct cause of the failure, considering that the damage was noticed in the summer (there was no snowload). The snow load amounts to about $25 \%$ of the total reaction. The couple of internal forces $M, N$ produced solely by the permanent loads would be within the safe range. The possible overloading of the structure in the winter period can be regarded as a factor which speeded up the failure, but did not initiate it. Nevertheless, it should be stated that the pillar needs to be strengthened because of the exceedance of the strength limit state.

\section{Causes of failure. Repair proposals}

It is usually difficult to point to a single cause of a failure or a structural collapse. In most cases it is the coexistence of several adverse circumstances, which only together reveal the structural defects. This was so also in this case.

In the authors' opinion the primary cause of the failure was the faultily constructed reinforcement, particularly:

- the absence of transverse reinforcement which should surround the longitudinal reinforcement and which would hinder the separation of the rebars from the concrete, the disruption of the interaction between the rebars, and the pulling out of the longitudinal rebars along the length of the lap;

- the absence of vertical reinforcement at the lateral edge of the column; this reinforcement could prevent the intensive propagation of cracks between the column and the foundation (in the years when the facility was built, the recommended maximum spacing of longitudinal rebars in a column was $40 \mathrm{~cm}[6])$;

- the too small length of the lap of the reinforcement extending from the foundation and that of the primary reinforcement, which did not exceed $65 \mathrm{~cm}$ (according to the then guidelines, the required length of anchorage was $56 \mathrm{~cm}$; moreover, it should have been increased even as much as two times since all the tension rods were connected together in one cross section [2]).

The next cause of the failure was the insufficient rebar cover $(5-15 \mathrm{~mm})$. This adversely affected the durability (concrete carbonation, reinforcement corrosion) and adhesion (the layer of concrete surrounding the rebars was too thin). Finally, another cause could be the overloading of the structure during periods of intensive snowfalls.

Taking into account the above circumstances, it was proposed to strengthen all the columns [7]. The strengthening was to consist in erecting $20 \mathrm{~cm}$ thick concrete walls on both sides of each of the columns (fig. 7). The walls were to take over the whole load from the roof. A transfer slab (a kind of cap) was to introduce uniform stresses into the padstone. The existing members and the strengthening ones were to be joined together by means of epoxy resin bonded rebars. The new structure was to transfer the entirety of the roof load.
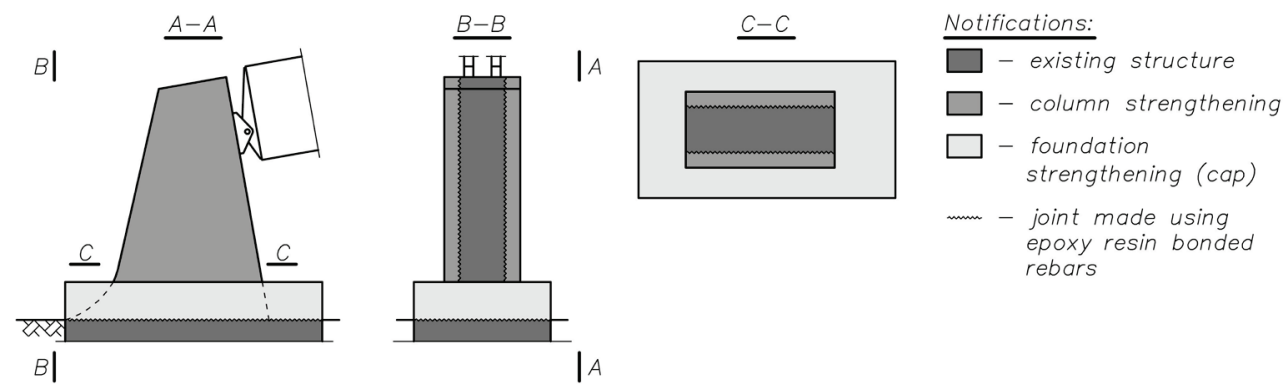

Fig. 7. Proposed way of strengthening [1]. 
The proposed way of strengthening was implemented in the autumn of 2016 (fig. 8).

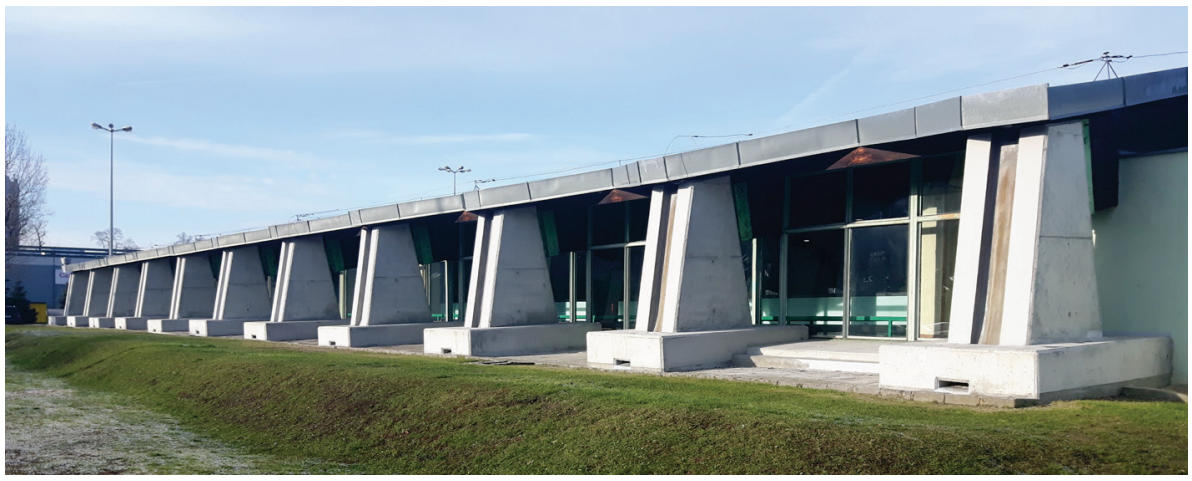

Fig. 8. Strengthened columns of south side.

\section{Conclusion}

The failure of the hall structure is an example of the construction negligence typical of the forty years after World War II in Poland. The low professional standards of the contractors and the shortage of materials were the source of many errors, and sometimes ended in tragedy. In the considered case, it was only a failure, which was a serious warning for the users of the facility. It was also a compelling reason for an inspection of all the key structural members of this facility.

The presented example illustrates well the construction practices of the bygone era. A characteristic feature of a large population of buildings from this period are very carefully prepared design documents and detailed specifications and drawings for construction. As opposed to this, the workmanship was poor and construction projects tended to be carried out recklessly, which would often end in structural collapses.

An important message for today is to develop a system of monitoring buildings, especially the ones characterized by a high level of risk (e.g. prestressed structures), and documenting their condition.

\section{References}

1. A. Ubysz, T. Trapko, M. Musiał, Emergency conditions of pillar supporting roof girder of sports and entertainment hall, Awarie Budowlane 2017. Wybrane zagadnienia diagnostyki, napraw i rekonstrukcji, 837-846 (Publishing House of West Pomeranian University of Technology, Szczecin, 2017) - in Polish

2. EN 1992-1-1. Eurocode 2: Design of concrete structures - Part 1-1: General rules and rules for buildings

3. K. Marsh, Autodesk Robot Structural Analysis Professional 2015: Essentials, (Marsh API LLC, United States, 2014)

4. EN 1990. Eurocode 0: Basis of structural design

5. B. Mosley, J. Bungey, R. Hulse, Reinforced Concrete Design to Eurocode 2. Sixth edition, (Palgrave Macmillan, United States, 2007)

6. J. Kobiak, W. Stachurski, Reinforced Concrete Structures, Vol. I, (Publishing House Arkady, Warsaw, 1984) - in Polish

7. A. Ubysz, T. Trapko, M. Musiał, Materiały Budowlane, 538, 44-45 (2017) - in Polish 